\title{
An Information Decomposition based on DSS--- The Example of Manufacturing Employment Growth
}

\author{
WANG Yi-bing ${ }^{1,}$, WANG Dan ${ }^{1, b}$ \\ ${ }^{1}$ School of Economics, Shandong University at Weihai, Weihai, Shandong 264209, China \\ awang_yibing@yahoo.com, ${ }^{b} 745538206 @ q q . c o m$
}

Keywords: manufacturing industry; employment growth; dynamic shift share; decomposition

\begin{abstract}
This paper uses the data between year 1998 to 2011 of 31 provinces and cities to analyze the difference in the employment growth of manufacturing industry in these provinces as well as in eastern, middle and western regions. The results show that industry structure and regional factors have different influences in the employment growth of manufacturing industry in different regions and provinces and these influences have dynamic changes in different time periods. The fluctuation of the effects of regional factor on employment is not very significant; however it is significant in the eastern region especially after the break of economic crisis. The effects of regional factor on employment are relatively stable in the middle and western region and suffer little from the economic crisis.
\end{abstract}

\section{Introduction}

The employment problem has been one of the top concerns of Chinese governments since China is a country with a large population. China's total economic output (GDP) increased by $1256.04 \%$ from 364.52 billion Yuan in 1978 to 458217.58 billion Yuan in 2011. But the employment growth is not that amazing compared to the economic growth. Total employment increased by only $97.29 \%$ from 40.15 million people in 1978 to 79.22 million people in 2010. In 2010 Chinese manufacturing output took up more than $19.8 \%$ in the world total manufacturing output, and became the world's biggest manufacturer since then. The Chinese manufacturing industry is such an important employer that there were 36.37 million people working in the urban manufacturing sector in 2011, which account for $27.9 \%$ of national urban employment. However the manufacturing employment showed a downward trend since the sub-prime credit crisis broke out in the U.S. in 2007. The number of urban employment in manufacturing was $28.8 \%$ of total urban employment in 2007 , falling to $28.2 \%$ in 2008 and falling further to $27.8 \%$ in 2009 . The manufacturing industry employment in 2009 decreased by $0.9 \%$ compared with that in 2007 . In view of this a research in manufacturing employment growth in different regions is necessary and imminent.

\section{Literature Review}

Some scholars believe that economic growth will generate employment growth [1]. The increase of labor input will increase the profits of firms, which will result in employment growth when labor productivity increases [2]. Some scholars researched the impact of industry diversity on employment and empirical results show that there exists a strong negative correlation between industrial diversity and unemployment. High industry concentration can result in high unemployment though it can make one industry highly specialized [3]. Satu Nurmi (2002) used panel data of 1981-1993 to analyze employment growth and found that the manufacturing industry employment growth decreased with the increase of industry scale [4]. Nobuo Kobayashi (2004) used the dynamic shift share method to analyze the impact of industrial structure changes on Japanese economy [5].

Some Chinese scholars analyzed the factors affecting the employment growth by using 29 provincial data of 2000-2009 and found that there is significant spatial correlation in inter-provincial employment and the spillover effects of employment between two adjacent 
provinces produce positive impacts on the provinces [6]. Other Chinese scholars analyzed China's employment growth in different regions [7].

In general few scholars made researches in the manufacturing employment growth from the aspect of industry structure and regional factors. In view of this limitation this paper uses dynamic shift-share method to analyze the manufacturing employment growth in different regions so as to make contributions in this field.

\section{Dynamic Shift-share Analysis}

In this paper, the dynamic shift-share method is used to analyze the manufacturing employment growth information. Shift-share analysis method, first proposed by Daniel Creamer in 1943, is one of the important information decomposition methods. The basic idea is that in a time range in a selected region, the selected regional development can be viewed as a dynamic process and the larger region where the economic activity (information) takes place can be used as a threshold reference or standard.

On the basis of previous studies this paper decomposes the information of $\Delta \mathrm{E}_{\mathrm{ir}}$, variation of manufacturing employment in industry $i$ in region $r$, into three parts: the national share $\left(\mathrm{NS}_{\mathrm{ir}}\right)$, industrial structure share $\left(\mathrm{IM}_{\mathrm{ir}}\right)$, regional share shift-share $\left(\mathrm{RS}_{\mathrm{ir}}\right)$. Expression

$$
\Delta \mathrm{E}_{\mathrm{ir}}=\mathrm{NS}_{\mathrm{ir}}+\mathrm{IM}_{\mathrm{ir}}+\mathrm{RS}_{\mathrm{ir}}
$$

The national share indicates that how the manufacturing industry employment will increase if it grows at the same rate as the national employment growth rate. The calculation of NS is as follows:

$$
N S=\sum E_{i r t} g_{n t}
$$

In Eq. 2 the $E_{\text {irt }}$ indicates employment of manufacturing industry $i$ in region $r$ in year $t$, the $g_{n t}$ is the national manufacturing industry employment growth in year $t$ :

$g_{n t}=\left(E_{t}-E_{t-1}\right) / E_{t-1}$

In Eq. 3 the $E_{t}$ is the national total manufacturing employment in year $t$. Industrial structure, shift-share refers to all industry employment growth in manufacturing provinces, according to the employment growth rate to achieve the growth of national manufacturing industry and the national employment rate of difference, which reflects the national reference standard, the merits of the regional manufacturing industry structure, its expression is:

$$
I M=\sum E_{\text {irt }}\left(g_{\text {int }}-g_{n t}\right)
$$

In Eq. 4 the $E_{\text {irt }}$ indicates employment of manufacturing industry $i$ in region $r$ in year $t, g_{\text {int }}$ is the overall employment growth rate of manufacturing industry $i$ in year $t$, which is calculated as:

$$
g_{\text {int }}=\left(E_{i t}-E_{i t-1}\right) / E_{i t-1}
$$

In Eq. 5 the $E_{i t}$ represents the national employment of manufacturing industry $i$ in year $t$. Regional structure, refers to the manufacturing industry according to the I employment growth rate of real growth achieved in accordance with the deviation between the corresponding increase in manufacturing industry in total employment growth rate achieved, reflect regional advantage compared with the national level, the manufacturing industry has in absorbing employment, its expression is:

$$
R S=\sum E_{\text {irt }}\left(g_{\text {irt }}-g_{\text {int }}\right)
$$

In Eq. 6 the $g_{\text {irt }}$ represents the employment growth rate of manufacturing industries $i$ in region $r$ in year $t$. The relation between TS and IM and RS is as follows:

$$
T S=I M+R S
$$

\section{Dynamic Shift-share Analysis Results}

The research time is divided into three periods: 1998-2001, 2002-2006, 2007-2011, the national growth share is calculated using "Statistical Yearbook of China" and "China Labor Statistical Yearbook" (NS), the industrial structure deviation from share (IM), area structure, shift-share method (RS). 
Table 1 The Regional Dynamic Shift-share Analysis

\begin{tabular}{|c|c|c|c|c|c|c|c|c|c|c|}
\hline \multirow{2}{*}{ ID } & \multirow{2}{*}{ Industry } & \multicolumn{3}{|c|}{$1998-2001$} & \multicolumn{3}{|c|}{$2002-2006$} & \multicolumn{3}{|c|}{$2007-2011$} \\
\hline & & NS & IM & RS & NS & IM & RS & NS & IM & RS \\
\hline \multirow{4}{*}{ 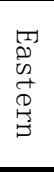 } & AGR & -908.3 & -1705.9 & 660.9 & 2309.9 & 1388.2 & 237.0 & 3384.9 & 402.5 & 3.6 \\
\hline & PRI & -1441.6 & -2020.1 & 2509.0 & 4048.6 & 4089.1 & 2564.6 & 5777.0 & -6615.6 & -3430.4 \\
\hline & TRA & -8586.8 & -5729.6 & 15596.0 & 23040.1 & 266.8 & 19073.9 & 33848.8 & -41660.5 & -3974.4 \\
\hline & $\mathrm{ADV}$ & -5976.1 & -3020.6 & 5103.0 & 15695.8 & 25793.4 & 16850.1 & 26136.8 & 7784.7 & 8324.7 \\
\hline \multirow{4}{*}{$\begin{array}{l}\frac{3}{2} \\
\stackrel{2}{2} \\
\frac{2}{0}\end{array}$} & AGR & -383.7 & -720.7 & 116.6 & 1773.2 & 1065.6 & -287.2 & 2332.0 & 277.3 & 51.5 \\
\hline & PRI & -107.4 & -150.5 & 706.2 & 1749.0 & 1766.5 & -863.8 & 2346.0 & -2686.6 & 3903.6 \\
\hline & TRA & -2441.7 & -1629.2 & -14826.2 & 13532.7 & 156.7 & -13689.7 & 16232.6 & -19978.8 & -2004.3 \\
\hline & $\mathrm{ADV}$ & -80.3 & -40.6 & -6338.9 & 7024.5 & 11543.6 & -11938.4 & 9608.9 & 2862.0 & -1696.1 \\
\hline \multirow{4}{*}{$\begin{array}{l}\vec{D} \\
D \\
0 \\
D \\
D \\
D \\
\end{array}$} & AGR & 1292.0 & 2426.7 & -777.6 & 541.8 & 325.6 & -25.9 & 908.7 & 108.1 & -50.6 \\
\hline & PRI & 1548.9 & 2170.6 & -3215.3 & 976.9 & 986.6 & -2300.1 & 1352.3 & -1548.6 & 603.2 \\
\hline & TRA & 11028.5 & 7358.8 & -769.8 & 6539.9 & 75.7 & -10568.0 & 8775.1 & -10800.2 & 6573.2 \\
\hline & ADV & 6056.4 & 3061.2 & 1235.9 & 3735.1 & 6138.0 & -9475.5 & 5193.8 & 1547.0 & -8463.2 \\
\hline
\end{tabular}

Table 1 shows that there exist significant differences in eastern, central and western regions during the period 1998-2001 from the aspect of RS values. The RS value is positive in some eastern regions, especially in Beijing (71814.46), Fujian (92817.87), Shandong (147536.3), Guangdong (119728.2 obvious location advantage). The location advantage of the traditional manufacturing industry in the above eastern regions is prominent. The central and western regions do not have such location advantage. The location advantage in central region is not significant compared with that in the eastern region. The RS values in the western region were mostly negative, showing that the western region does not have the location advantage which negatively affects the manufacturing employment in this region. During the period 2002-2006 the regional advantages in the central and western regions were relatively stable while the regional advantage in the eastern regions changed significantly after joining into the WTO. In the period of 2007-1011, the RS value in the eastern coastal provinces changed dramatically, for example, the value of RS in Shandong decreased by 51164 compared with that in 2002-2006, the regional advantages in the economic crisis in the central and western regions are more evident, for example, the RS value in Tibet and Hunan increased by 19665.43 and 93173.51 respectively.

\section{Conclusions}

The results show that in the 14 years from 1998 to 2011, the effects of industry structure have different impacts on employment growth in different provinces and regions. The overall impact of regional structure didn't change much, but the regional factors in eastern regions were more complex and dramatic, especially after economic crisis. Regional effects on manufacturing employment in central and western regions were relatively, the effects of economic crisis were small. The eastern region suffers more to external shocks than the central and western regions.

\section{Reference}

[1]Martine Carre, David Drouot. Pace Vs Type the Effect of Economic Growth on Unemployment and Wage Pattern [J], Review of Economics Dynamics, 2004, Vol. 7(3): 737-757

[2] Pissarides Chirstopher A. Equilibrium Unemployment Theory [M], Cambridge: MIT Press, 2000 [3]Oded Izraeli and Kevin J. Murphy. The Effect of Industrial Diversity on State Unemployment Rate and Per Capita Income [J], Annals of Regional Science, 2003, Vol.37 (1): 1-14

[4]Satu Nurmi. Plant Size, Age and Employment Growth in Finnish Manufacturing [J], Helsinki School of Economics, 2002, 4(2):129-142

[5]Nobuo Kobayashi. Industrial Structure and Manufacturing Growth During Japan's Bubble and Post-Bubble Economies[J], Regional Studies, 2004, Vol. 38.(4): 429-444

[6] Liu Zhixiong, Liang Dongmei, The empirical analysis and regional comparisons of employment growth in China [J]. Industrial Technology Economics, 2011, (1): 39-45 
[7] Cai Fang, Wang Meiyan. Informal employment and labor market development of Chinese urban employment growth of [J]. Dynamic Economics, 2004, (2): 24-28 